\title{
A Study of Burn Injury Cases in Pediatric Age Group in Vindhya Region of India
}

\author{
Authors \\ Dr Lal Mani Sing ${ }^{1}$, Dr Vinod Yedalwar ${ }^{2}$ \\ ${ }^{1,2}$ Associate Professor, Department of Surgery S.S. Medical College Rewa MP \\ Corresponding Author \\ Dr Vinod Yedalwar \\ Associate Professor, Department of Surgery S.S. Medical College Rewa MP, India \\ Email:drvyedalwar@gmail.com
}

\begin{abstract}
Background: Burns in children are reported to be amongst the most prevalent traumatic injuries around the world, most of which occurring in accidental domestic environment, that are preventable. With this study, we aim to suggest measures that may be taken to prevent burns in children.

Methods: Retrospective analysis of data of children with burns, up to 15 years of age, admitted to the Burns Unit of S.S. Medical College associated S.G.M. Hospital Rewa Madhya Pradesh, India during the study period of June 2014 to may 2015 was done. For the purpose of analysing, these children were divided into three groups based on their age.

Results: A total of 129 pediatric burn cases were studied. Female children (51.93\%) were more commonly affected. $93.02 \%$ burns were accidental in etiology. Scalds were the most common mode of injury in toddler age group (0-5 years). Overall mortality was $10.89 \%$

Conclusions: This study highlights the etiology and risk factors for burns in children of different age groups, which help in establishing safety measures that can be included in preventive programs. Through a combination of prevention strategies and improved burns care, considerable progress can be made not only in lowering the death rates, but also in achieving the goal of physical, social and psychological rehabilitation in pediatric burn patients.

Keywords: burn injury, pediatric age, Vindhya Region.
\end{abstract}

\section{Introduction}

Burn is described as one of the leading causes of injury throughout the world, and is one of the most frequent causes of hospitalization. Burn is a major cause of morbidity and mortality, and it is the fourth most common type of trauma worldwide $^{[1,2]}$. Burn is a major issue on public health in terms of infection control and cost of treatment in both developing and developed countries, and burn in pediatric range from minor to severe injuries. Burns from hot drinks, food, steam, or other hot liquids are common causes of burn injuries to young children compared to other burn injuries ${ }^{[2]}$. Therefore, it is important to educate parents, make them aware of the potential danger in the home environment and how to prevent common burn accidents. 
Burns is a global health problem, accounting for an estimated 310,000 deaths annually. In developing countries, it is reported to be the third most common cause of death in children aged between 5 and 14 years. The global incidence (all ages) is 1.1 per 100,000 , and it varies with geographic location, socio-economic status, ethnic group, age and sex.1 Over $95 \%$ of burns occur in low \& middle income countries, with highest incidence occurring in World Health Organization (WHO) Southeast Asia region. In India, over $1,000,000$ people are moderately or severely burnt every year. ${ }^{[1]}$

\section{Methods}

Retrospective analysis of data of children with burns, up to 15 years of age, admitted to the Burns Unit of S.S. Medical College associated S.G.M. Hospital Rewa Madhya Pradesh, India during the study period of June 2014 to may 2015 was done. Data was collected by reviewing patient hospital records, photographic records and discharge summaries. Data regarding age, gender distribution, etiology, mechanism of injury, percentage of burns and depth of burns, treatment modality, duration of hospital stay and mortality were collected and analysed.

\section{Results}

A total of 129 pediatric cases aged between 5months and 14 years, were admitted in the Burns Unit of Sanjay Gandhi Memorial Hospital, during the study period from July 2016 to June 2017. This was amongst a total number of 510 patients admitted to the burns unit during this period, accounting for an incidence of $25.29 \%$ of pediatric burns. Female children's (51.93\%) were more commonly affected compared to Male (48.06\%). High incidence $(40.31 \%)$ noted in children's bellow 5 years of age. In our study scald was the most common mode of injury, occurring in $60.47 \%$ cases, flame in $33.33 \%$ cases, followed by electrical burns in $4.65 \%$ cases, $93.02 \%$ of burns were accidental in etiology, followed by $6.20 \%$ cases of homicidal. (Table 1 , 2)

On the basis of age children were divided into three groups for the data analyzing purpose. Majority of children affected belonged to age group of up to 5 years accounting for 52(40.31). The other two groups of 6 to 10 years and 11 to 15 years accounted for $36.43 \%$ and $23.26 \%$ respectively. Most common etiology was accidental in nature in all the age groups. Hot liquid (Scald) was the most common mode of injury in infants and toddlers (0-5 years), mainly due to tipping over or accidental fall into containers with hot tea, boiling milk accidents. Whereas, in older children (6 to 15 years), thermal (flame) burns was the most common mode of injury followed by electrical burns (Table 3). Thermal burns in our study, was mainly seen in younger girls who were assigned to do household work of cooking and boiling water using Choolhas (fire place on kitchen floor using firewood as fuel), chimni (homemade lamp) and kerosene stoves and both of which are predominantly used by the rural population of, India. Incidences of loose clothing catching fire while lighting lamps were noted. Cracker burns accounted for thermal burns mainly in boys. Electrical burns were due to contact with live wires while flying kites on the terraces with low lying high tension electric wires and also due to mishaps with household electrical appliances.

High incidence of burn noted at home $117(90.70 \%)$ specially in kitchen $70(59.82 \%)$ [n=117home] maximum children's get burn injury who's parents was farmer $33.33 \%$ followed by laberer $31.01 \%$ and $40.31 \%$ noted in mother was house wife as compared to laborer mother $34.10 \%$, high incidence of burn $54.26 \%$ occurred in living in joint family verses $45.74 \%$ those living in Nuclear family. $82.94 \%$ patients belong to rural area and $52.71 \%$ living in Kachcha house. (Table 4)

Various treatment modalities that were followed in our centre included collagen sheet dressing for superficial burns, operative procedures like 
scharotomy, debridement and skin grafting for II degree deep burns and fasciotomy, flap cover and amputations were required in III to IV degree deep electrical burns. In our study, $70 \%$ of instances needed surgical intervention of one form or the other.

Majority of burns in younger children and toddlers was of superficial depth owing to scald injury predominantly, that required conservative treatment in the form of regular dressings or liquid paraffin sheet dressing. Whereas, II degree deep to III and IV degree burns were more common in the older children who required multiple surgical interventions.

It was noted that high mortality rates was seen in younger age groups flam burn irrespective of the percentage of burns. And also, the mortality rate was directly proportional to the extent of burns in all age groups of children. Death rate in this study was $10.89 \% \%$ with a total of 13 deaths (Table 5).

\begin{tabular}{|c|c|c|c|c|}
\hline \multicolumn{5}{|c|}{ Table 1: Incidence of all burn patients and children burn patients } \\
\hline $\begin{array}{c}\text { Total number of } \\
\text { patients admit in } \\
\text { surgical ward }\end{array}$ & $\begin{array}{c}\text { Total number of burn } \\
\text { patients }\end{array}$ & Incidence (\%) & $\begin{array}{c}\text { Total number of } \\
\text { burn patients }<14 \\
\text { years }\end{array}$ & $\begin{array}{c}\text { Incidence } \\
(\%)\end{array}$ \\
\hline 8946 & 510 & 5.70 & 129 & 25.30 \\
\hline
\end{tabular}

\begin{tabular}{|l|c|c|c|}
\hline \multicolumn{4}{|l|}{ Table 2: Age- and sex-wise distribution } \\
\hline Age in years & Male (\%) & Female $(\%)$ & Total $(\%)$ \\
\hline Up to 5 & 24 & 28 & $52(40.31)$ \\
\hline $6-10$ & 22 & 25 & $47(36.43)$ \\
\hline $11-15$ & 16 & 14 & $30(23.26)$ \\
\hline Total & $62(48.06)$ & $67(51.93)$ & 129 \\
\hline
\end{tabular}

\begin{tabular}{|l|c|c|}
\hline \multicolumn{3}{|l|}{ Table 3: cases according to patients variable factors(n=129) } \\
\hline Factors & number of patients & $\%$ \\
\hline mode of burn & 43 & 33.33 \\
\hline Flame & 78 & 60.47 \\
\hline Scald & 06 & 4.65 \\
\hline Electric & 02 & 1.56 \\
\hline Chemical & \multicolumn{2}{|l|}{} \\
\hline Cause of injury & 120 & 93.02 \\
\hline Accidental & 01 & 0.78 \\
\hline Suicidal & 08 & 6.20 \\
\hline Homicidal & \multicolumn{2}{|l|}{} \\
\hline Source of burn & 18 & 13.95 \\
\hline Chimney & 14 & 10.85 \\
\hline Chulha & 6 & 4.65 \\
\hline Cooker & 72 & 55.81 \\
\hline Hot Liquid (dal, water, milk, oil, tea, vegetable) & 4 & 3.10 \\
\hline Kerosene & 6 & 4.65 \\
\hline Open fire & 1 & 0.78 \\
\hline Cracker fire & 6 & 4.65 \\
\hline Electrocution & 2 & 1.56 \\
\hline Acid &
\end{tabular}




\begin{tabular}{|c|c|c|}
\hline factors & $\begin{array}{c}\text { Number of cases } \\
(\mathbf{n}=129)\end{array}$ & $\%$ \\
\hline \multicolumn{3}{|l|}{ Fathers Occupation } \\
\hline Farmer & 43 & 33.33 \\
\hline Laborer & 40 & 31.01 \\
\hline Office worker & 28 & 21.70 \\
\hline Shopkeeper & 6 & 4.65 \\
\hline Driver & 3 & 2.33 \\
\hline Garbage collector & 5 & 3.87 \\
\hline Photographer & 1 & 0.77 \\
\hline Mechanic & 2 & 1.55 \\
\hline Cook & 1 & 0.77 \\
\hline \multicolumn{3}{|l|}{ Mothers occupation } \\
\hline House wife & 52 & 40.31 \\
\hline Office worker & 33 & 25.58 \\
\hline Laborer & 44 & 34.10 \\
\hline \multicolumn{3}{|l|}{ Family size (members) } \\
\hline $1-5$ & 73 & 56.59 \\
\hline $6-10$ & 40 & 31.01 \\
\hline$>10$ & 16 & 12.40 \\
\hline \multicolumn{3}{|l|}{ Place of sustaining Trauma } \\
\hline \begin{tabular}{|l|l|} 
At home & kitchen \\
\end{tabular} & $70-59.82 \%$ & 54.26 \\
\hline Living room & 21 & 16.28 \\
\hline Dining room & 22 & 17.05 \\
\hline Courtyard & 4 & 3.10 \\
\hline temple & 2 & 1.55 \\
\hline Marriage hall & 3 & 2.33 \\
\hline Restaurant & 1 & 0.77 \\
\hline School & 1 & 0.77 \\
\hline Agree culture farm & 2 & 1.55 \\
\hline Work place & 3 & 2.33 \\
\hline \multicolumn{3}{|l|}{ Family type } \\
\hline Joint & 70 & 54.26 \\
\hline Nuclear & 59 & 45.74 \\
\hline \multicolumn{3}{|l|}{ Residential locality } \\
\hline Rural & 107 & 82.94 \\
\hline Urban & 22 & 17.05 \\
\hline \multicolumn{3}{|l|}{ Type of house } \\
\hline Kachcha & 68 & 52.71 \\
\hline Pakka house & 20 & 15.50 \\
\hline Pakka house designed & 29 & 22.48 \\
\hline Tent & 12 & 9.30 \\
\hline
\end{tabular}

\begin{tabular}{|l|c|c|}
\hline \multicolumn{3}{|l|}{ Table 5 Distribution of Mortality } \\
\hline Sex & Total & Total n0. Of Death \\
\hline Male & 62 & $5(8.06 \%)$ \\
\hline Female & 67 & $8(11.94 \%)$ \\
\hline Total & 129 & $13(10.89 \%)$ \\
\hline
\end{tabular}


Table 6 Intervention measures Prevention strategies ${ }^{[6]}$

\begin{tabular}{l}
\hline Improve socio-economic status · Improved parental education \\
- Improved housing \\
- Provision of basic amenities e.g. water, smoke alarms \\
- Regulate and design industrial products e.g. kerosene stoves, storage of flammable substances \\
- Child supervision - particularly those with impairments \\
Community programmes - Appropriate child supervision - particularly for the impaired \\
- Parental education - specific to burns \\
- General public - store flammable material away from the home \\
Improve design standards - Improve sleepwear flammability standards \\
- Introduction of new and less flammable fabrics \\
- Design of more close-fitting dresses \\
- Redesigning cooking packages e.g. upright soup packages \\
Education and awareness - Use of hot water \\
- Leaving children unattended \\
- Electric apparatus \\
- Chemical substances \\
- Workplace \\
- Kitchen appliance - to be kept out of reach of child \\
- Heating devices \\
First aid knowledge \\
- Vigilance when child unwell \\
- Install microwave ovens at height accessible only to adults or older children \\
- Microwave oven not to be operated by a child younger than seven years \\
- Microwave food to be stirred and temperature-tested before serving or eating \\
- Place children in a safe area e.g. high chair or playpen during food or beverage preparation \\
- Hot beverages and foods to be kept out of children's reach \\
\hline
\end{tabular}

\section{Discussion}

Burns are an important cause of preventable injury, especially in the pediatric age group. Burn injury historically carried a poor prognosis, but with advancements in fluid resuscitation and advent of surgical intervention, survival has become an expectation even for patients with severe burns. Continued improvements in critical care and progress in skin bioengineering herald a future in which functional and psychological outcomes are equally important as survival alone $^{[1,3]}$

In our study, 8946 patients were admitted in surgical wards among which 510 patients had burn injuries. The total incidence of burn patients in the burn unit of surgical wards was $5.70 \%$. A total of 129 patients under age of 15 years were admitted in burn unit of surgical ward which was $25.30 \%$ of total burn cases.

In our study $40.31 \%$ children were up to 5 years of age some other studies also noted same in their studies ${ }^{[1,4,5,6,7,8]}$. The higher incidence in this age group is due to the curious nature of infants and toddlers and the urge to mostly pull and push things around. They end up getting injured when containers, pots, or pans containing hot fluids overturn and pour on them.

In the current study female $51.93 \%$ were more affected to burn injury than males $48.06 \%$. But many studies noted more incidence in male or equal incidence ${ }^{[1,2,4,5,6,8]}$ in this region of Indian pupils give less importance to female as compared to male so level of care and observation get low in female that may be the cause of high incidence in female

In our study, scalds were the main cause of burn in the majority of patients, similar to other studies. ${ }^{[1,2,4,5,6,7,8,9]}$ Flame burn is the second most common cause of pediatric burn injury. Flame burns are generally caused by chimni (homemade lamp,), choola and other open fires. Electric burn and chemical burns were also seen. The rate of 
electric and chemical burn were lower when compared to other studies in literature ${ }^{[2,10,11]}$ All burns were accidental. Hot water was the most common cause of scald burns in our study, other causes of scald burns were hot milk, tea dal water, hot oil, .

Most of the injuries $90.70 \%$ occurred in domestic circumstances with accidental 93.02\%.aetiology being most common ${ }^{[10,11,12,13-15]}$ other studies also shows high incidence in the domestic circumstance $^{[1,2,4,5,6,7,8]}$. In our study most common area was kitchen to get injury.

In our study maximum children's were injured in group of farmer, house wife and belongs to rural area living in kachca house even in public living in joint family injured more as compared to other professionals suggest lack of attention exposure to outdoor play specially in road and public places other than play ground that may be lack of knowledge in illiterate and poor knowledge about safety and security. Farmers work in agriculture farm and left kids at home alone without supervision so have more prone to injury. This could be explained by the lack of safety measures in unsupervised kids.

In our study, the mortality was $10.89 \%$ which is less than $13.64 \%^{[1]}, 15 \%{ }^{[5]}, 13.88 \%{ }^{[12]}$ and $19.7 \%^{[17]}$. Although it appears that the incidence of burns is largely unchanged over time, the mortality rates seem to have dropped. The drop in mortality rates may be attributable to better resuscitation, and management, Application of fluid resuscitation formula has markedly reduced the prevalence of death due to resuscitation failure. The need to educate people about firesafety in the home environment, living condition and social welfare has been suggested.

There are some limitations of study. For example, the reported incidence is only of hospitalized patients; and hence, the actual incidence of the general population may be different. The data collected was only from single institute. The number of patients is small; a longer duration of study is required.
Burns in general, irrespective of the etiology poses socioeconomic burdens on the patient and family members resulting in morbidity and nonproductivity. ${ }^{[14]}$ In general, infants and toddlers depend solely on their mothers and caregivers for care and support they need, implying that caregivers have to invest time which could otherwise be used to work to take care of their kids hence causing economic burden. This current study shows scald injuries as high as $69.04 \%$ and so burns preventive measures, especially towards scald prevention at homes, should be paramount, since the home serves as the highest place of childhood scalds occurrence. ${ }^{[15]}$

\section{Conclusion}

Infants and toddlers are more prone for accidental scald burns, whereas older children are more affected with accidental thermal and electrical burns, all occurring in domestic home environment. Therefore, parental counseling regarding potential dangers of household circumstances, fire safety and first-aid is most important in pediatric burns.

A dedicated multi-disciplinary team with good infrastructure exclusively for burn patients and strict protocols followed at every stage of the treatment is utmost important for better outcome in pediatric burns. Through a combination of prevention strategies and improved burns care, considerable progress can be made not only in lowering the death rates, but also in achieving the goal of physical, social and psychological rehabilitation in pediatric burn patients.

\section{References}

1. Powar RS et al. Epidemiological study of pediatric burns at a tertiary care centre in South India Int J Community Med Public Health. 2016 May;3(5):1242-1246

2. Kurane SB, Ugane S. A retrospective study of pediatrics burns at general hospital in rural India. Int J Med Sci Public Health 2014; 3:1235-1237. 
3. Endorf FW, Gibran NS. Schwartz's Principles of Surgery. Brunicardi CF. Burns.9th ed. New York, NY: McGrawHill; 2010:197-208.

4. Rashid KJ, Babakir-Mina M, Abdilkarim DA (2017) Characteristics of Burn Injury and Factors in Relation to Infection among Pediatric Patients. MOJ Gerontol Ger 1(3): 00013.DOI:10.15406/mojgg.2017.01.0001 3

5. Kannan VV, Sundari SM, Anandan H. Epidemiological Study of Pediatric Burns at a Tertiary Care Center - Retrospective Study. Int J Sci Stud 2017;5(2):90-93.

6. Dhopte et al. Epidemiology of pediatric burns and future prevention strategies - a study of 475patients from a high-volume burn center inNorth India Burns \& Trauma (2017) 5:1

7. Pius Agbenorku et al Pediatric burns mortality risk factors in a developing country's tertiary burns intensive care unit Int J Burn Trauma 2013;3(3):151-158

8. Peddi M, Segu SS, Ramesha K T. The persistent paradigm of pediatric burns in India: An epidemiological review. Indian J Burns 2014;22:93-7

9. Verma SS, Srinivasan S, Vartak AM. An epidemiological study of 500 paediatric burn patients in Mumbai, India. Indian J Plast Surg 2007;40:153-7.

10. Haberal M, Uçar N, Bilgin N. Epidemiological survey of burns treated in Ankara, Turkey and desirable burnprevention strategies. Burns 1995;21:601-6.

11. Anlatici R, Ozerdem OR, Dalay C, Kesiktas E, Acarturk S, Seydaoglu G. A retrospective analysis of 1083 Turkish patients with serious burns. Burns 2002;28:231-7.
12. Mehta MA, Bhatia VY, Sharma BP. A study of burns in pediatric age group. Indian J Burns 2013;21:55-8.

13. Sheridan RL, Remensnyder JP, Schnitzer JJ, Schulz JT, Ryan CM, Tompkins RG. Current Expectations for Survival in Pediatric Burns. Arch Pediatr Adolesc Med 2000; 154:245-9.

14. Tyack ZF, Ziviani J. What influences the functional outcome of children at 6 months post-burn? Burns 2003; 29:433-44.

15. Yates J, McKay M, Nicholson AJ. Patterns of scald injuries in children - has anything changed? Irish Med J 2011; 104:263-5.

16. Gupta M, Gupta OK, Goil P. Paediatric burns in Jaipur, India: An epidemiological study. Burns 1992; 18:63-7. 